\title{
EMOTIONAL INTELLIGENCE, JOB SATISFACTION, WELLBEING AND \\ ENGAGEMENT: EXPLAINING ORGANIZATIONAL COMMITMENT AND \\ TURNOVER INTENTIONS IN POLICING
}

\section{INTRODUCTION}

Policing is typical of social occupations considered stressful because it involves dealing with people and making speedy decisions that could have serious physical, health, social or other impacts upon the public (Kyriacou, 2001). Bakker and Heuven (2006) and Hochschild (1983) noted that police officers, as emotional workers, are exposed to emotionally demanding interpersonal interactions (such as death, illness, accidents, crimes) on a daily basis, requiring them to regulate their feelings and expressions.

In addition, police officers in many OECD countries such as Australia, UK and NZ have experienced increased stress due to bigger workloads, predominantly resulting from a major shift in governance to focus on output and accountability (Dick, 2011; Hoque et al., 2004; Long, 2003). Public sector reform rhetoric has focused on improving service delivery, but in practice, the driving force of change has been in achieving efficiencies - sometimes at the expense of quality service delivery (Long, 2003). Researchers have identified the high stress involved for employees delivering services, within an environment of rationalized budgets to an increasingly vocal public demanding more services (Hoque et al., 2004; Long, 2003; Wright, 2002).

Increasingly, police officers are in the spotlight to behave and act in particular ways, especially in response to community demands and expectations (Dick, 2011; Long, 2003) and preliminary research suggests that the outcomes for police officers have been negatively affected. Policing is a form of emotional labour and the effort involved in protecting the community, while behaving in a "client-focused" manner but restrained by fiscal constraints (Hoque et al., 2004), has been shown to have a negative impact upon police officer 
engagement and job outcomes (e.g. Wright et al., 2006). While much research has shown that the emotional intelligence of police officers has an impact upon their work outcomes, there are few empirical studies showing the effect of emotional intelligence upon police officer retention. Hence, the current study is important because it examines the effects of emotional intelligence on the job satisfaction, wellbeing and engagement of police officers in explaining their organizational commitment and subsequently, their turnover intentions. The primary research question is:

How does the emotional intelligence of police officers affect their job satisfaction, wellbeing and engagement and in turn, their perceptions of organizational commitment and turnover intentions?

\section{Conceptualising Emotional Intelligence}

Emotions are an important part of being human and they affect our actions and motivations for behaviour and practices (Stanley and Burrows, 2005) which, in turn, affect our perceptions of psychological health (Slaski and Cartwright, 2003). Mayer and Salovey (1997:10) argued that emotional intelligence (EI) comprises the interrelated skills of selfawareness, managing emotions, motivating oneself, empathy and handling relationships, defining EI as:

the ability to perceive accurately, appraise, and express emotion; the ability to access and/or generate feelings when they facilitate thought; the ability to understand emotion and emotional knowledge; and the ability to regulate emotions to promote emotional and intellectual growth.

Law and Wong (2002) adopted a similar definition of EI as Mayer, Salovey and Caruso (2000). Law, Wong and Song (2004) added to this earlier work by operationalising EI as a construct separate from personality dimensions and showed that it could predict job performance. In contrast, Joseph and Newman (2010: 71) argued, 'the EI literature has yet to investigate exactly what self-report EI is'. They conceptualised personality dimensions and cognitive ability as antecedents of EI and found that the link with job performance 
depends largely on which dimension of EI is used. These conflicting research findings suggest a contested terrain and the need for further research examining the impact of EI. Similar to Law and Wong (2002), the current study also adopts the definition of EI derived from Mayer, Salovey and Caruso (2000).

This is an important management issue because without the ability to understand our emotions and those of others, employees faced with numerous interactions with the public (often under intensive and/or difficult situations) are likely to control/minimise their exposure to negative emotions (such as working with child abuse cases as discussed in Wright et al., 2006). They may do this by avoiding or manipulating their exposure to negative situations or by controlling how they react to negative situations. However, if employees cannot successfully manipulate either such exposure or reactions, these aspects are likely to negatively impact upon their job satisfaction and performance.

\section{Job Satisfaction}

Job satisfaction in the current study is defined as what employees feel about their work, which may be negative or positive (Spector, 2003). Research suggests that satisfied employees are time-effective at work, likely to minimize their sick leave and have lower turnover intentions (Spector, 1997). Additionally, Meyer et al., (2002) identified a significant relationship between job satisfaction and affective commitment. Other researchers have found an inverse relationship between work stress and other job-related outcomes, such as job satisfaction, for Australian nurses (Joiner and Bartram, 2004). Police officers are similar to nurses in that their occupations require extensive public interaction and quick decision-making possibly impacting significantly upon the public's physical and psychological health and wellbeing. 
Further, previous research by Sy et al. (2006) found a positive relationship between EI and job satisfaction as employees who have high EI are more likely to have higher level of job satisfaction because these employees are better at appraising and regulating their feelings and those of others in the workplace which in turn positively impact on morale and job satisfaction. The positive relationship between EI and job satisfaction is also supported in a nursing sample (Güleryüz, Güney, Aydın, and Aşan, 2008) where nurses who have higher EI tend to report higher satisfaction with their job. Therefore, we expected there would be a relationship between police officers' emotional intelligence and job satisfaction.

\section{Wellbeing}

Wellbeing has been examined by numerous researchers across different disciplines and has multiple definitions, conceptualizations and measurements. An assessment of available literature identifies three categories: a) psychological wellbeing (which examines employees' levels of satisfaction with workplace processes and practices), b) physical wellbeing (employees' health outcomes, for example from stress and accidents) and c) social wellbeing (the quantity and quality of workplace social networks, plus employees' perceptions of fairness and equity) (Grant et al., 2007). Psychological wellbeing is defined as employees' attitudes and feelings about the work context (Diener, 2000). It differs from job satisfaction because it encapsulates more than an employee's satisfaction with the job, and includes satisfaction with both tangible and intangible work context aspects. For police, we expected a positive relationship between emotional intelligence and wellbeing.

Additionally, researchers have identified a link between wellbeing and job outcomes, such as job satisfaction (Judge and Watanabe, 1993; Wright and Cropanzano, 2000). This is of particular relevance, because police officers have been shown to suffer from negative wellbeing as a result of the emotional nature of their daily work (e.g. Wright 
et al., 2006). Hence, we expected police officers' levels of wellbeing to be positively associated with their job satisfaction.

\section{Engagement}

The concept of employee engagement is relatively new to management and consequently there is limited empirical research about this new construct and the factors it affects (Saks, 2006). However, engagement is important to examine within the public sector because it influences employees' performance, which affects how satisfied the public are with services provided (Harter et al., 2002). In this study, we followed Kahn (1990), defining engagement as a work situation where employees find work meaningful and consequently they want to, and can, invest in their work to achieve personal and career benefits. The end product of being engaged is an energetic and passionate employee. May et al. (2004) argued that engagement describes employees experiencing the antithesis of "burnout", because they are involved in work at a cognitive and emotional level.

It is management's responsibility to provide a working environment that generates and maintains employee engagement. Research suggests that the antecedents of employee engagement are effective leadership and co-worker relationships, interesting work tasks and the resources to perform their jobs well, plus just rewards (May et al., 2004). Richman (2006) argued that engagement is likely to be influenced more by management practices, the work environment and climate than by the age, gender or personality of employees. Further, Bakker et al. (2007) found that when job resources (supportive supervisor and/or organizational climate) were plentiful, it helped to shield teachers against the negative effects of high job demands. They argued that this was because the job resources helped to reduce stress, thereby addressing potential burnout. Hence, we expect police officers reporting lower levels of wellbeing to be less engaged with their organization. 


\section{Affective Commitment and Turnover Intentions}

Commitment is closely related to engagement, because committed employees are also engaged in the job (Meyer and Allen, 1991). Allen and Meyer (1990) defined affective commitment as the emotional attachment to and identification with an organization, making the employee loyal and attached to the organization. Additionally, Coffman and GonzalezMolina (2002) argued that the greater an employee's level of affective commitment, the stronger their engagement with the job. Affective commitment results from employees being treated and valued fairly and justly (Luchak and Gellatly, 2007), especially in the case of public sector employees (Reid et al., 2008). Affective commitment is an important measure because Meyer and Allen (1997) and Pitt et al. (1995) found an inverse relationship between employees' affective commitment and their intentions to leave. Supporting that, Hartmann and Bambacas (2000) found that low affective commitment predicted higher intention to quit for casual academic staff in an Australian tertiary institution.

Despite the above empirical evidence on organizational commitment, scholars such as Dick (2011) claimed there are insufficient studies on organizational commitment in police forces and that more research is needed. In addition, the empirical findings on the antecedents of organizational commitment in policing are inconclusive. For instance, the study by Noblet et al. (2009) of an Australian police agency showed that job demand and control have inconsistent effects on job satisfaction and organizational commitment. Dick's (2011) study on a sample of English police officers showed that organizational and workplace experiences of how officers are managed were found to be the strongest influences on their organizational commitment.

These findings are important because turnover in the law enforcement sector is a major issue (e.g., Lynch and Tuckey, 2008). Previous research identified a positive relationship between dis-satisfaction at work and turnover intentions (Griffeth et al., 2000). Further, organizational commitment was found by Lum et al. (1998) to have the strongest 
and most direct impact upon turnover intentions. Supporting this,, in organizations where employees exhibit higher levels of commitment, lower absenteeism and turnover rates resulted (Meyer and Allen, 1997) and Meyer et al. (2002) similarly found that high affective commitment predicted lower turnover levels.

While the literature provides understanding of the antecedents of turnover intentions, few studies have investigated these for police officers (Lynch and Tuckey, 2008). Research by Jaramillo et al. (2005) in six law enforcement agencies found that job satisfaction, among other factors, was the best predictor of organizational commitment. Their study also showed a significant relationship between organizational commitment and police officers' intentions to leave. Brough and Frame (2004) found a negative relationship for police officers between job satisfaction and the amount of leave taken plus the lack of opportunity for advancement in the organization. However, few studies have examined the causal relationship between job satisfaction, affective commitment and the turnover intentions of police officers. Consequently, we focus on examining the causal relationships in the current study.

\section{Age and Gender}

Previous research has found that gender impacts upon EI (Ponterotto, et al., 2011). Van Rooy et al. (2006) argued that research is converging on the opinion that females score higher than males on measures of EI. Additionally, Joseph and Newman (2010) supported the view that females score higher on EI. Petrides and Furnham (2006) noted that age interacted with gender such that older females showed higher EI compared with younger females. However, others found insignificant gender differences in relation to EI (e.g., Whitman et al., 2009). Hence, further research is needed to investigate the effects of age and gender on EI. 


\section{Hypotheses}

The current study contributes to the literature by examining the strength and direction of the causal relationships from police officers' emotional intelligence of their job satisfaction, wellbeing, engagement, affective commitment, and turnover intentions. The hypothesized relationships will be tested by using Partial Least Squares (PLS) path analysis, a form of structural equation modelling (see Figure 1). For police officers:

Hypothesis 1. There is a positive relationship between emotional intelligence and job satisfaction.

Hypothesis 2. There is a positive relationship between emotional intelligence and wellbeing.

Hypothesis 3. There is a positive relationship between wellbeing and job satisfaction.

Hypothesis 4. There is a positive relationship between wellbeing and employee engagement.

Hypothesis 5. There is a positive relationship between wellbeing and affective commitment.

Hypothesis 6. There is a negative relationship between wellbeing and turnover intentions.

Hypothesis 7. There is a positive relationship between job satisfaction and employee engagement.

Hypothesis 8. There is a positive relationship between job satisfaction and affective commitment.

Hypothesis 9. There is a negative relationship between job satisfaction and turnover intentions.

Hypothesis 10. There is a positive relationship between employee engagement and affective commitment.

Hypothesis 11. There is a negative relationship between affective commitment and turnover intentions.

Hypothesis 12. There is a negative relationship between employee engagement and turnover intentions. 
Hypothesis 13. Female police officers will have higher levels of emotional intelligence than male officers.

Hypothesis 14. Older police officers will have higher emotional intelligence than younger officers.

Hypothesis 15. There is an interaction effect between gender and age on emotional inteeligence. (is this the appropriate hypothesis derived from the lit review? If not, the interaction effect has to be taken out of this paper\}

Insert Figure 1 about here

\section{METHODS}

\section{Sample and data analysis}

A self-complete anonymous questionnaire was offered to police officers attending training in one region of an Australian state police service over a four month period. In total, 750 surveys were distributed and we received 193 usable surveys (a response rate of 26\%). The majority of the respondents was male $(\mathrm{N}=132,68.4 \%)$ and held the rank of senior constable $(31.6 \%)$. Average tenure in their current police station was less than 5 years and most had been employed with this police force for 3-10 years.

We used SmartPLS (Ringle et al., 2005), a form of latent path model, to test our path model. Survey data were input into SPSS v.17 for Windows to conduct descriptive statistical analysis.

\section{Measures}


We used previously validated scales to operationalize the constructs in the path model, all of which are reflective measures. Except for age and gender, these were measured on a sixpoint Likert-type scale, ranging from 1 (strongly disagree) to 6 (strongly agree).

Emotional Intelligence was operationalised using Wong and Law's (2002) Emotional Intelligence Scale. An exploratory factor analysis was conducted using Principal Component Analysis and Varimax rotation, resulting in the same four sub-scales as Wong and Law (2002): self-emotion appraisal, others' emotion appraisal, use of emotion, and regulation of emotion. These were then used to form a reflective measure within the path model (composite reliability coefficient of 0.84). Employee Engagement was measured using a nine-item scale from Schaufeli and Bakker (2003) including, "I find the work that I do full of meaning and purpose" (composite reliability coefficient of 0.91). Job Satisfaction was measured using the four-item scale from Johlke and Durham (2000) with a composite reliability coefficient of 0.89 . The items included, "I feel that my job is valuable". Affective Commitment measured police officers' commitment to their organization using Allen and Meyer's (1990) eight-item affective commitment scale, which has a good internal reliability as shown by a composite reliability coefficient of 0.87 . Items included, "I feel a strong sense of belonging to my organization". Wellbeing was measured using a four-item scale by Brunetto et al. (2011) to measure psychological wellbeing, which addresses Van der Doef and Maes' (1999) criticisms about ignoring the impact of the job situation itself. It has a composite reliability coefficient of 0.89 . Items included "Most days I feel a sense of accomplishment in what I do at work". Turnover Intentions, the dependent variable, was measured using a three-item scale adopted from Meyer, Allen and Smith (1993). It has a composite reliability coefficient of 0.95 . Items included, "It is likely that I would search for a job in another organization". Age was categorised into (a) under 30 years, (b) between 30 to 45 years, and (c) over 45 years. Gender was sought by asking the respondents to indicate whether they were male (1) or female (0). 


\section{Validity and reliability}

The path model developed in Figure 1 has seven independent constructs and one dependent construct. According to Green (1991: 503), the sample size in the current study is sufficient to achieve a medium effect size of 0.80 . We assessed the significance of PLS parameter estimates by using the bootstrap option incorporated within the SmartPLS (Ringle et al., 2005) software. Bootstrapping with 500 sub-samples is carried out to provide extra confidence that the results are not sample-specific. Discriminant validity of the reflective constructs is assessed by using Fornell and Larcker's (1981) measure of average variance extracted (AVE).

In the current study, we tested for the effect of common method bias by conducting Harman's ex-post one factor test (Podsakoff and Organ, 1986). All the variables used in the study were entered into an unrotated factor analysis. The analysis showed that there were 10 factors (with eigen values greater than 1.0), which explained $72.4 \%$ of the variance.

We evaluated the quality of the structural model by using R-square of the dependent variables, the Stone-Geisser Q-square test for predictive relevance (Chin, 2010) and the global criterion for goodness of fit (Tenenhaus et al., 2005) for PLS models. Chin (2010) recommended that the communality and redundancy Q-square indices must be greater than zero, for the model to have predictive relevance. Two separate analyses with 10 and 25 omission distances were undertaken to test the stability of the findings. Since the values are stable for both omission distances and all of the Q-squares were greater than zero, we were confident that the model is stable and the predictive relevance requirement is satisfied.

\section{RESULTS}

Table 1 shows the means, standard deviations, AVE and correlations between the variables. The model has discriminant validity as the correlation matrix shows that all the diagonal elements are greater than the corresponding off-diagonal elements. Using the formulae 
proposed by Tenenhaus et al. (2005) for calculating the global criterion of goodness of fit, the model has a large goodness of fit (goodness of fit index of 0.445). In addition, the path model explained $29 \%$ of the dependent variable, turnover intentions.

Insert Table 1 about here

As shown in Table 2 and Figure 2, the path from emotional intelligence to job satisfaction was positive and statistically significant (coefficient $=0.2085$, t-statistic $=3.1889$, $\mathrm{p}<.001)$. The path from emotional intelligence to self-reported wellbeing was statistically significant $($ coefficient $=0.379$, t-statistic $=4.0059, \mathrm{p}<.001$ ). There were four statistically significant paths from self-reported wellbeing to job satisfaction (coefficient $=0.5935, \mathrm{t}$ statistic=10.36, $\mathrm{p}<.001)$, employee engagement $($ coefficient $=0.4318, \mathrm{t}$-statistic $=4.5367$, $\mathrm{p}<.001$ ), affective commitment (coefficient $=0.3473$, t-statistic $=3.7273, \mathrm{p}<.001$ ) and turnover intentions $($ coefficient $=-0.1883, \mathrm{t}$-statistic $=2.0381, \mathrm{p}<.05)$. The path from job satisfaction to employee engagement was found to be positive and statistically significant (coefficient $=0.4023, \mathrm{t}$-statistic $=4.8121, \mathrm{p}<.001)$. The path from employee engagement to affective commitment was statistically significant (coefficient $=0.3856$, t-statistic $=4.3403$, $\mathrm{p}<.001)$ and from affective commitment to turnover intention, the path was found to be negative and statistically significant (coefficient $=-0.4659$, $\mathrm{t}$-statistic $=4.9472, \mathrm{p}<.001)$. The path from employee engagement to turnover intention was negative and significant (coefficient=-0.1879, t-statistic=2.0467, $\mathrm{p}<.05$ ). Having tested for the effects of age and gender, using path analysis, we found no prediction effect of EI for gender (coefficient= 0.19, t-statistic $=0.5320$, n.s.), age (coefficient $=-0.01$, t-statistic $=0.0479$, n.s. $)$, or the interaction item, age by gender (coefficient $=-0.06$, t-statistic $=0.1696$, n.s. $)$. 
Insert Table 2 about here

Moderation was tested by creating a new variable (age $\mathrm{x}$ gender) and a path was created leading into EI. Path analysis showed that age interaction with gender is not a moderator of EI (coefficient=-0.062, t-statistic $=0.1696$, n.s.). Additionally, we found that affective commitment partially mediates the relationship between employee engagement and turnover intentions (Sobel's test: $3.2626, \mathrm{p}=.0011, \mathrm{n.s.}$ ).

Insert Figure 2 about here

\section{DISCUSSION AND IMPLICATIONS}

This study reports the perceptions and opinions of police officers who are typically affected by the negative consequences of policing's emotional aspects. Few studies have examined the human resource management implications of the emotional aspects of labour. Our path analyses showed a number of interesting findings which provided support for the majority of our hypotheses. This study suggests that, overall, EI predicted police officers' perceptions of wellbeing and job satisfaction, which influenced engagement and affective commitment and subsequently, negatively affected turnover intentions. Further, the findings found that female police officers have higher EI than males, supporting Ponterotto et al. (2011).

Second, as predicted, as police officers' emotional intelligence increased, so did their reported wellbeing. This is not perhaps surprising, given that emotional intelligence is the capacity to regulate one's external behaviour to appear appropriate to the circumstances 
(Mayer and Salovey, 1997), including negative situations (Law et al., 2004). Hence, this finding contributes to what is important and required in contemporary police work and has potential implications for ensuring appropriate selection criteria for police officers. It may be just as important for a modern day police officer to be emotionally aware as it is for them to be physically fit and knowledgeable about the law.

Third, as police officers' wellbeing increased, so did their job satisfaction, engagement and organizational commitment, leading to lower levels of turnover intentions. These results support earlier research by Bakker et al. (2007), Luchak and Gellatly (2007), May et al. (2004), and Reid et al. (2008) about the relationships between some of these variables. However, other research has not identified the path relationship between all these variables, and therefore this is another contribution of our study. While there is minimal previous research linking wellbeing and affective commitment, there is research that links wellbeing with job satisfaction; yet in this study, job satisfaction was not significantly related to affective commitment, in contrast with Judge and Watanabe (1993).

Fourth, May et al. (2004) and Richman (2006) argued that engagement is influenced by the support and resources available at work, including supervision and management practices, while Luchak and Gellatly (2007) and Reid et al. (2008) argued similarly about affective commitment. The findings from this study add new knowledge in showing that engagement is predicted by wellbeing and job satisfaction and in turn predicts police officers' commitment and turnover intentions. The findings have implications for police departments charged with implementing the new agenda focused on service delivery, but funded to enforce the reality of rationalized policing (Hoque et al., 2004; Long, 2003).

Fifth, we found that police officers' job satisfaction predicts their engagement at work and their affective commitment. This result was expected by us and links between some of these variables are supported by other research (Judge and Watanabe, 1993); however, other research has not identified the path relationship between all three variables. 
The finding has implications for management because previous research suggests that engagement is a function of management and the work environment (May, et al. 2004; Bakker, et al. 2007) and energetic and passionate employees predict committed employees and reduced turnover intentions.

Sixth, we found that age, gender, and the interaction between the two, were not significant predictors of EI. While the links between age, gender and EI remain underresearched, the results of our study support the proposition that EI level does not vary significantly with age.'

Finally, our study found that police officers' affective commitment mediates the negative relationship between their engagement at work and their turnover intentions. This result provides some positive direction to partly address police officer retention challenges and there are clear implications for senior police management in these results.

Two paths that were not significant are the paths from job satisfaction to affective commitment (H8) and from job satisfaction to turnover (H9). The findings from this study are in contrast to previous cross-sectional studies (such as Meyer et al., 2002), showing a significant relationship between job satisfaction, affective commitment and turnover. Instead, our findings support research by Currivan (1999), who similarly found a nonsignificant relationship in their longitudinal SEM analysis. One possible explanation is that the factors affecting job satisfaction for police officers (such as the nature of policing work) are different than those affecting their organization commitment (such as management factors). More research is required examining the relationship between job satisfaction, affective commitment and turnover intentions across a range of different types of occupations to better understand the associations.

\section{Managerial Implications}


Our study provides support for the argument that policing requires the effective use of emotional intelligence. It highlights the importance of police officers monitoring their work experiences and identifies that emotional intelligence affects their job satisfaction and wellbeing, which affects their engagement and organizational commitment, and then turnover intentions. Other implications emerge from the detection that EI is linked to turnover intentions. This is crucial in contemporary policing because the retention of valued, experienced and highly trained officers affects policing outcomes. Policy implications include that policing HRM practices should consider the EI ability of police officers for both selection and development purposes. In an effort to increase retention, therefore, the consequences for wellbeing and job satisfaction and consequently, employee engagement and organisational commitment, must be considered.

In addition to resource effective policing, senior management should consider the implications of selecting police officers that demonstrate high EI because they are likely to perform certain policing tasks better (such as negotiating with difficult suspected perpetrators). Additionally, management may need to consider training options for police officers so that they can understand how their behaviour affects those they are expected to protect and serve, and to provide officers with more knowledge about how to use language that may defuse explosive interactions with difficult perpetrators. From our findings, it is argued that in well-acknowledged emotional labour work, such as policing, teaching and nursing, human resource practices could thereby be better targeted to achieve more costeffective HRM outcomes.

Finally, two possible causes of police job dissatisfaction and disengagement that appear to warrant policy change are: (1) inadequate supervisory resourcing and support; and (2) unrealistic performance targets. Further research is warranted to identify the extent of any negative attitudinal/affective influence in each case. 


\section{Limitations and future research implications}

There are a number of limitations in this study. The study is limited to police officers in one police service and therefore further studies are required in other police services and using other types of employees. Another limitation is the use of self-report surveys causing common methods bias. To reduce common method bias when the criterion and predictor variable cannot be measured in different contexts, as in this study, Podsakoff et al. (2003) recommend separating the measurement of the criterion and predictor variables psychologically and ensuring the survey is anonymous. The survey applied these recommendations. The relatively low response rate must be noted as a potential further limitation. Additionally, the responses reported above cannot be assumed to represent the perceptions of all police officers or all police stations in that police service.

One challenge of voluntary surveys is that the research does not uncover the reasons why some chose not to participate. These reasons may be significant, yet remain concealed. One explanation could be that some police officers were concerned for their own confidentiality within the results. Another reason could be that some felt that others would better represent their views. Secondly, there will be differences in the management of police officers between the various police stations, yet these differences are not identified within this paper. Finally, while the relationship testing suggests a linear relationship, far more research is required in order to examine whether the EI-outcome relationships could be non-linear. Future research should extend this study to examine the impacts of supervision practices and relationships with employees. plus perceived organizational support, upon these variables.

\section{CONCLUSIONS}

This study sought to understand the path relationship leading from police officers' emotional intelligence to various performance-related outcomes and finally to turnover 
intentions. Within a context of retention challenges within Australia's police forces, any guidance as to how better to manage police officers is keenly sought. With the caveat that emotional intelligence is a contested concept that has multiple interpretations, this paper indicates that emotional intelligence warrants being included in retention strategies/plans because of its impact upon turnover intentions. In particular, these findings suggest that police officers' emotional intelligence affects their job satisfaction, wellbeing and engagement and thereby, their perceptions of affective commitment and subsequently and notably, their turnover intentions.

The results of this study underscore the complex role that emotional intelligence plays in turnover decisions. While we have made some progress in understanding why police officers leave and what factors may be important to that intention, there remains much to be learned. Remaining important issues are the extent to which resources are available to police officers to undertake their jobs, and the supervision and management practices used to encourage such undertakings. Police management needs to ensure that police officers are competent and trained, but also provided with sufficient resources and supportive supervision, so that their work performance can be optimized and, importantly, their likely retention increased. 


\section{REFERENCES}

Allen, N. and Meyer, J. 1990. 'The measurement and antecedents of affective, continuance, and normative commitment to the organization', Journal of Occupation Psychology, $61,1-18$

Bakker, A.B. and Demerouti, E. 2007. 'The job demands - resources model: State of the art', Journal of Managerial Psychology, 22, 309 - 328.

Bakker, A.B. and Heuven, E. 2006. 'Emotional dissonance, burnout, and in-role performance among nurses and police officers', International Journal of Stress Management, 13, 423-440.

Brough, P. and Frame, R. 2004. 'Predicting police job satisfaction and turnover intentions: The role of social support and police organizational variables', New Zealand Journal of Psychology, 33, 8-16.

Brunetto, Y., Farr-Wharton, R. and Shacklock, K. H. 2011 'Using the Harvard HRM model to conceptualise the impact of changes to supervision upon HRM outcomes for different types of public sector employees', International Journal of Human Resource Management. 22, 3, 553-573

Burke, R. J. and Greenglass, E. R. 2000. 'Hospital restructuring and nursing staff well being: the role of coping', International Journal of Stress Management, 7, 49-59.

Chin, W. W. 2010. 'How to write up and report PLS analyses', In W. W. Chin (Ed.), Handbook of Partial Least Squares Analysis: Concepts, Methods and Applications: 645-688. Berlin Heidelberg: Springer.

Coffman, C. and Gonzalez-Molina, G. 2002. Follow This Path: How the World's Greatest Organizations Drive Growth by Unleashing Human Potential. New York: Warner.

Cooper, C. L. and Cartwright, S. 1994. 'Healthy mind; healthy organization - a proactive approach to occupational stress', Human Relations, 47, 455-472. 
Currivan, D 1999. The causal order of job satisfaction and organizational commitment in models of employee turnover Human Resource Management Review, 9 (4) 495-524

Daniels, K. and Guppy, A. 1994. 'Occupational stress, social support, job control and psychological well-being', Human Relations, 47, 1523-1538.

Daniels, K. and Guppy, A. 1997. Stressors, locus of control, and social support as consequences of affective psychological well being, Journal of Occupational Health Psychology, 2, 156-174.

Dick, G. 2011. The influence of managerial and job variables on organizational commitment in the police. Public Administration, 89, 2: 557-76.

Diener, E. 2000. 'Subject wellbeing: The science of happiness, and a proposal for a national index', American Psychology, 55, 34-43.

Fornell, C. and Larcker, D. F. 1981. 'Evaluating structural equation models with unobservable variables and measurement error', Journal of Marketing Research, 18, $39-50$.

Grant, A. M., Christianson, M. K., and Price, R. H. 2007. 'Happiness, health, or relationships? Managerial practices and employee well-being tradeoffs', Academy of Management Perspectives, 21, 51-63.

Green, S. B. 1991. 'How many subjects does it take to do a regression analysis?' Multivariate Behavioral Research, 26, 499-510.

Griffeth, R. W., Hom, P. W., and Gaertner, S. 2000. 'A meta-analysis of antecedents and correlates of employee turnover: Update, moderator tests, and research implications for the next millennium', Journal of Management, 26, 463-488.

Güleryüz, G., Güney, S., Aydın, E.M., and Aşan, Ö. 2008. 'The mediating effect of job satisfaction between emotional intelligence and organisational commitment of nurses: A questionnaire survey', International Journal of Nursing Studies, 45, 11, $1625-1635$. 
Harter, J., Schmidt, F., and Hayes, T. 2002. 'Business-unit-level relationship between employee satisfaction, employee engagement, and business outcomes: A metaanalysis', Journal of Applied Psychology, 87, 268 - 279.

Hartmann, L. C. and Bambacas, M. 2000. 'Organizational commitment: A multi method scale analysis and test of effects', International Journal of Organizational Analysis, 8, 89-108.

Hochschild, A. 1979. 'Emotion work, feeling rules, and social structure', American Journal of Sociology, 85, 551-575.

Hochschild, A. 1983. The Managed Heart: Commercialization of Human Feeling. Berkeley: University of California Press.

Hoel, H., Einarsen, S., and Cooper, C. L. 2003. 'Organisational effects of bullying', In S.E. Einarsen, H. Hoel, D. Zapf, and C.L. Cooper (Eds.), Bullying and Emotional Abuse in the Workplace: International Perspectives in Research and Practice, 145-161. London: Taylor and Francis.

Hoque, Z., Arends, S., and Alexander, R. 2004. 'Policing the police service: A case study of the rise of "new public management" within an Australian police service', Accounting, Auditing and Accountability Journal, 17, 59-84.

Jaramillo, F., Nixon, R. and Sams, D. 2005. 'The effect of law enforcement stress on organizational commitment', Policing: An International Journal of Police Strategies and Management, 28, 321-336.

Johlke, M. C. and Duhan, D. F. 2000. 'Supervisor communication practices and service employee job outcomes', Journal of Service Research, 3, 154-165.

Joiner, T. and Bartram, T. 2004. 'How empowerment and social support affect Australian nurses' work stressors', Australian Health Review, 28, 56-64.

Joseph, D and Newman, D., 2010, 'Emotional intelligence: an integrative meta-analysis and cascading model', Journal of Applied Social Psychology, 95, 54-78. 
Judge, T. and Watanabe, S. 1993. 'Another look at the job satisfaction-life satisfaction relationship', Journal of Applied Psychology, 78, 939-948.

Kahn, W. A. 1990. 'Psychological conditions of personal engagement and disengagement at work', Academy of Management Journal, 33, 692-724.

Kyriacou, C. 2001. 'Teacher stress: directions for future research', Educational Review, 53, 27-35.

Law, K., Wong, C. and Song, L.J. 2004. 'The construct and criterion validity of emotional intelligence and its potential utility for management studies', Journal of Applied Psychology, 89, 483-496.

Long, M. 2003. 'Leadership and performance management', In T. Newburn (Ed.), Handbook of Policing, 625-658. Devon UK: Willan Publishing Ltd.

Luchak, A. and Gellatly, I. 2007. 'A comparison of linear and nonlinear relations between organizational commitment and work outcomes', Journal of Applied Psychology, 92, 786-793.

Lynch, J.E. and Tuckey, M. 2008. 'The police turnover problem: Fact or fiction?' Policing: An International Journal of Police Strategies and Management, 31, 6-18.

Lum, L., Kervin, J., Clark, K., Reid, F., and Sirola, W. 1998. 'Explaining nursing turnover intent: Job satisfaction, pay satisfaction, or organizational commitment? 'Journal of Organizational Behavior, 19, 305-320.

May, D., Gilson, R., and Harter, L. 2004. 'The psychological conditions of meaningfulness, safety and availability and the engagement of the human spirit at work', Journal of Occupational and Organizational Psychology, 77, 11- 37.

Mayer, J. and Salovey, P. 1997. 'What is emotional intelligence?' In P. Salovey and D. Sluyter (Eds.), Emotional Development and Emotional Intelligence: Educational Implications, 3-34. New York: Basic Books. 
Mayer, J., Salovey, P \& Caruso, D 2000. 'Models of Emotional Intelligence' in R. Sternberg, (ed) Handbook of Intelligence, Cambridge University Press, Cambridge.

Meyer, J. and Allen, N. 1997. Commitment in the Workplace: Theory, Research and Application. Thousand Oaks: Sage Publications.

Meyer, J. P. and Allen, N. J. 1991. 'A three-component conceptualization of organizational commitment', Human Resource Management Review, 1, 61-89.

Meyer, J. P., Allen, N. J., and Smith, C. A. 1993. 'Commitment to organizations and occupations: extension and test of a three component conceptualization', Journal of Applied Psychology, 78, 538-551.

Meyer, J. P., Stanley, D. J., Herscovitch, L., and Topolnytsky, L. 2002. 'Affective, continuance, and normative commitment to the organization: A meta-analysis of antecedents, correlates, and consequences', Journal of Vocational Behavior, 61, 2052.

Noblet, A., J. Rodwell and A. Allisey. 2009. 'Job stress in the law enforcement sector', Stress and Health, 25, 111-120.

Parasuraman, S., Granrose, C. S., and Greenhaus, J. H. 1992. 'Role stressors, social support, and well being among two career couples', Journal of Organizational Behavior, 13, $339-356$.

Petrides, K. and Furnham, A. 2006. 'The role of trait emotional intelligence in a genderspecifific model of organizational variables', Journal of Applied Social Psychology, $36,552-569$.

Pitt, M., Leyland, F., Foreman, S. K., and Bromfield, D. 1995. 'Organisational commitment and service delivery: Evidence from an industrial setting in the UK', International Journal of Human Resource Management, 6, 369-389.

Podsakoff, P. M. and Organ, D. W. 1986. 'Self-reports in organizational research: Problems and prospects', Journal of Management, 12, 531-544. 
Podsakoff, P. M., MacKenzie, S. B., Lee, C. A., and Podsakoff, N. P. 2003. 'Common method biases in behavioral research: A critical review of the literature and recommended remedies', Journal of Applied Psychology, 88, 879-903.

Ponterotto, J. G., Ruckdeschel, D. E., Joseph, A. C., Tennenbaum, E. A., and Bruno, A. 2011. 'Multicultural personality dispositions and trait emotional intelligence: an exploratory study', Journal of Social Psychology, 151(5), 556-576.

Reid, M. F., Riemenschneider, C. K., Allen, M. W., and Armstrong, D. J. 2008. 'Information technology employees in state government: A study of affective organizational commitment, job involvement, and job satisfaction', American Review of Public Administration, 38, 41-61.

Richman, A. 2006. 'Everyone wants an engaged workforce how can you create it?' Workspan, 49, 36-39.

Ringle, C. M., Wende, S., and Will, A.; SmartPLS 2.0 (beta); www.smartpls.de. [accessed 15 August 2011].

Saks, A. M. 2006. 'Antecedents and consequences of employee engagement', Journal of Managerial Psychology, 21, 600 - 619.

Schaufeli, W. and Bakker, A. 2003. UWES Utrecht Work Engagement Scale. Preliminary Manual, Utrecht University: Occupational Health Psychology Unit.

Slaski, M. and Cartwright, S. 2003. 'Emotional intelligence training and its implications for stress, health and performance', Stress and Health, 19, 233-239.

Spector, P. E. 1994. 'Using self-reported questionnaires in OB research: A comment on the use of a controversial method', Journal of Organizational Behavior, 15, 385-392.

Spector, P. and Fox, S. 2003. 'Reducing subjectivity in the assessment of the job environment and development of the Factual Autonomy Scale (FAS)', Journal of Organizational Behavior, 24, 417-432. 
Stanley, R.O. and Burrows, G.D. 2005. The role of stress in mental illness: The practice. In C. L. Cooper (Ed.), Handbook of Stress Medicine and Health. London: CRC Press.

Sy, T., Tram, S and O'Hara, L.A. 2006. 'Relation of employee and manager emotional intelligence to job satisfaction and performance', Journal of Vocational Behavior, $68,461-473$.

Tenenhaus, M., Vinzi, V. E., Chatelin, Y.-M., and Lauro, C. 2005. 'PLS Path Modeling', Computational Statistics and Data Analysis, 48, 159-205.

Van der Doef, M. and Maes, S. 1999. 'The job demand-control-support model and psychological well-being: A review of 20 years of empirical research', Work and Stress, 13, 87-114.

Van Rooy, D. L., Dilchert, S., Viswesvaran, C., and Ones, D. S. 2006. Multiplying intelligences: Are general, emotional andpractical intelligence equal? In K. D. Murphy (Ed.), A critique of emotional intelligence: 235-262. Mahwah, NJ: Erlbaum.

Whitman, D. S., Van Rooy, D. L., Viswesvaran, C., and Kraus, E. 2009. 'Testing the second-order factor structure and measurement equivalence of the Wong and Law Emotional Intelligence Scale across gender and ethnicity'. Educational and Psychological Measurement, 69, 6, 1059-1074.

Wong, C. S. and Law, K. 2002. 'The effects of leader and follower emotional intelligence on performance and attitude: An exploratory study', Leadership Quarterly, 13, 233274.

Wright, A. 2002. Policing: An Introduction to Concepts and Practice, Devon UK: Willan Publishing Ltd.

Wright, R., Powell, M.B., and Ridge, D. 2006. 'Child abuse investigation: An in-depth analysis of how police officers perceive and cope with daily work challenges', Policing: An International Journal of Police Strategies and Management, 29, 498512. 
Wright, T. A. and Cropanzano, R. 2000. 'Psychological well-being and job satisfaction as predictors of job performance', Journal of Occupational Health Psychology, 5, 8494. 
TABLE 1: Mean, Standard Deviation, AVE and Correlations

\begin{tabular}{|c|c|c|c|c|c|c|c|c|}
\hline & Mean $^{\mathbf{a}}$ & SD & 1 & 2 & 3 & 4 & 5 & 6 \\
\hline Age & - & 0 & & & & & & \\
\hline Gender & - & - & & & & & & \\
\hline Emotional Intelligence & 4.92 & 0.54 & $\underline{0.75}$ & & & & & \\
\hline Job Satisfaction & 4.40 & 0.87 & $.41 * * *$ & $\underline{0.82}$ & & & & \\
\hline Wellbeing & 4.30 & 0.87 & $.36 * * *$ &.$\overline{65 * * *}$ & $\underline{0.82}$ & & & \\
\hline Employee Engagement & 4.32 & 0.80 & $.43 * * *$ & $.67 * * *$ &.$\overline{69 * * *}$ & 0.74 & & \\
\hline Affective Commitment & 3.87 & 0.99 & $.29 * * *$ & $.52 * * *$ & $.59 * * *$ & $.62 * * *$ & $\underline{0.75}$ & \\
\hline Turnover Intention & 2.87 & 1.40 & -.13 & $-.33 * * *$ & $-.41 * * *$ & $-.31 * * *$ & $-.49 * * *$ & 0.93 \\
\hline
\end{tabular}

$\mathrm{N}=193$

${ }^{\text {a }}$ Mean: ' 1 ' = strongly disagree, to ' 6 ' = strongly agree

Note: Discriminant analysis for reflective scales are shown in diagonal as underlined

$* * * \mathrm{p}<.001$ 
TABLE 2: Results of Partial Least Squares Path Analysis

\begin{tabular}{l|c|c|c}
\hline Paths & $\begin{array}{c}\text { Path } \\
\text { coefficient }\end{array}$ & $\begin{array}{c}\text { t- } \\
\text { statistic }\end{array}$ & $\begin{array}{c}\text { Sig. } \\
\text { level }\end{array}$ \\
\hline H1. Emotional Intelligence $\rightarrow$ Job Satisfaction & 0.21 & 3.4326 & $* * *$ \\
H2. Emotional Intelligence $\rightarrow$ Wellbeing & 0.38 & 4.2154 & $* * *$ \\
H3. Wellbeing $\rightarrow$ Job Satisfaction & 0.6 & 10.1663 & $* * *$ \\
H4. Wellbeing $\rightarrow$ Employee Engagement & 0.43 & 4.2567 & $* * *$ \\
H5. Wellbeing $\rightarrow$ Affective Commitment & 0.35 & 3.6445 & $* * *$ \\
H6. Wellbeing $\rightarrow$ Turnover Intention & -0.19 & 1.968 & $*$ \\
H7. Job Satisfaction $\rightarrow$ Employee Engagement & 0.4 & 4.6467 & $* * *$ \\
H8. Job Satisfaction $\rightarrow$ Affective Commitment & 0.03 & 0.3847 & n.s. \\
H9. Job Satisfaction $\rightarrow$ Turnover Intention & -0.09 & 0.9685 & n.s. \\
H10. Employee Engagement $\rightarrow$ Affective Commitment & 0.39 & 4.1219 & $* * *$ \\
H11. Affective Commitment $\rightarrow$ Turnover Intention & -0.47 & 4.5373 & $* * *$ \\
H12. Employee Engagement $\rightarrow$ Turnover Intention & 0.19 & 1.8503 & n.s. \\
H13. Gender $\rightarrow$ EI & 0.19 & 0.532 & n.s. \\
H14. Age $\rightarrow$ EI & 0.01 & 0.0479 & n.s. \\
H15. Age x Gender $\rightarrow$ EI & -0.06 & 0.1696 & n.s. \\
\hline
\end{tabular}

Note:

$* \mathrm{p}<.05 ; * * * \mathrm{p}<.001$

n.s. not significant 
FIGURE 1: Proposed Path Model

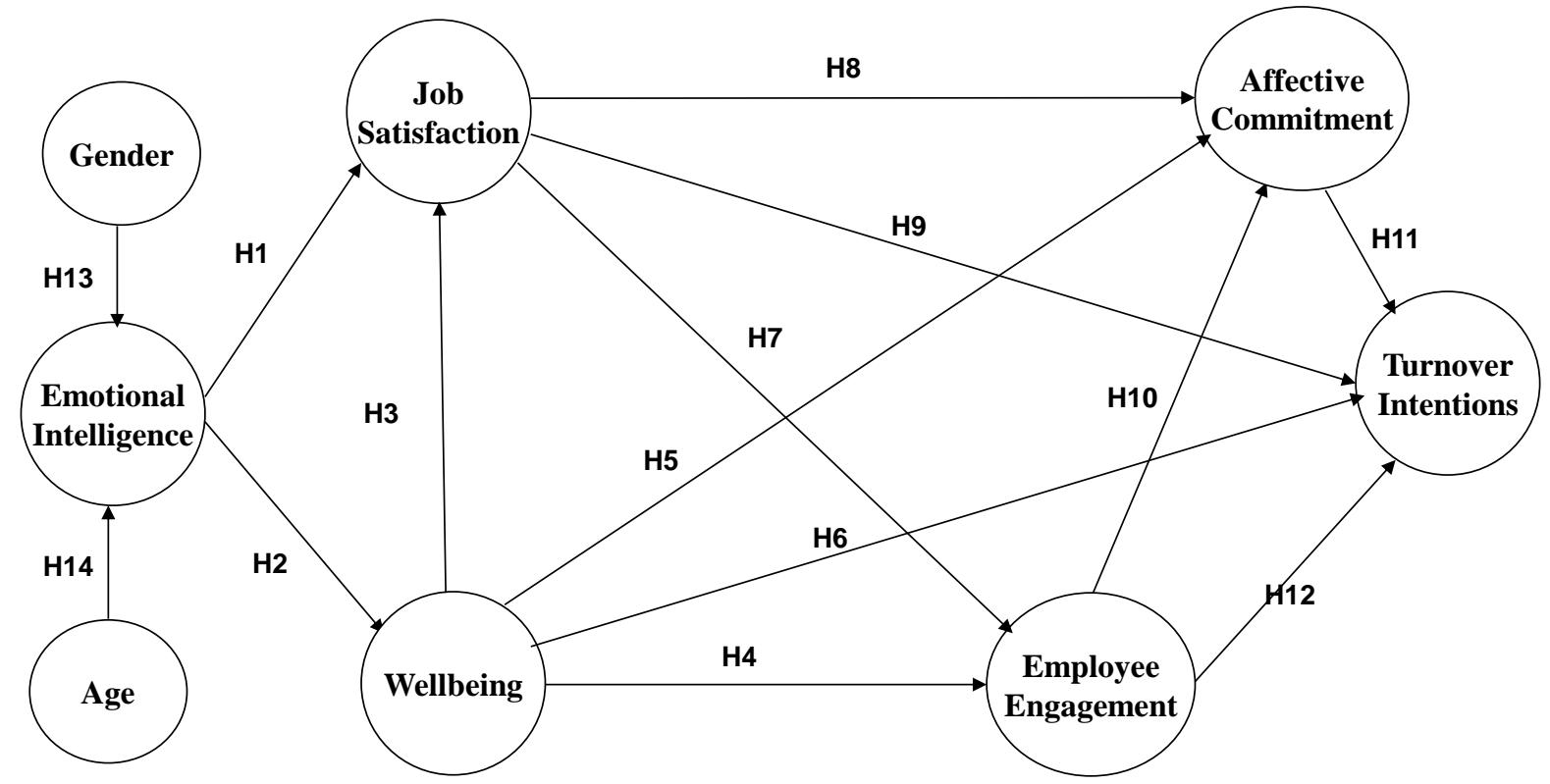


FIGURE 2: Emotional intelligence, job satisfaction, wellbeing, engagement, organizational commitment and turnover intentions

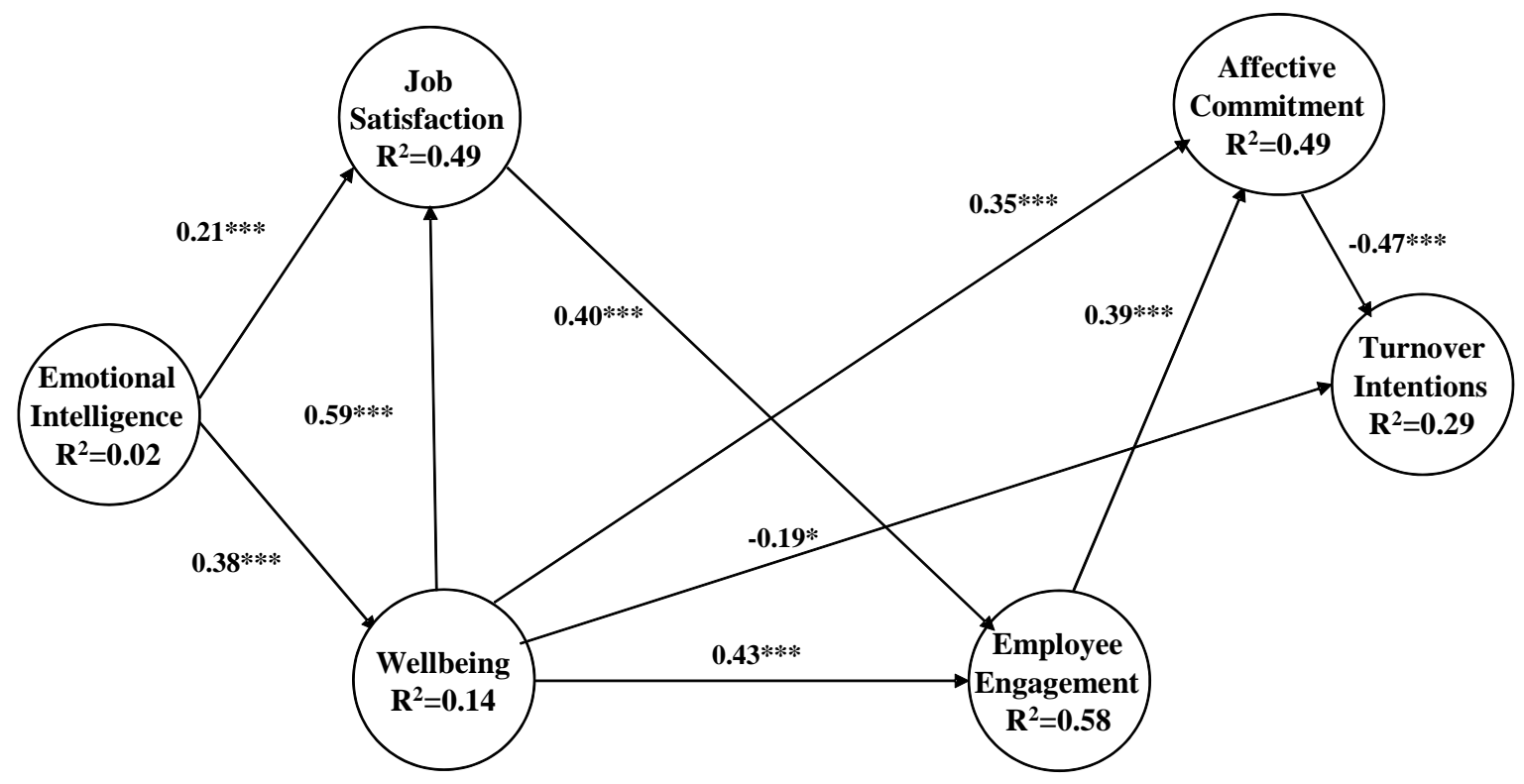

Note: Only statistically significant paths are reported in this figure. 